\title{
Validation of an RP-HPLC Method for the Determination of Asenapine Maleate in Dissolution Media and Application to Study In Vitro Release from Co-Crystals
}

\author{
Suhair S. Al-Nimry * and Mai S. Khanfar (D) \\ Department of Pharmaceutical Technology, Jordan University of Science and Technology, P.O. Box 3030, \\ Irbid 22110, Jordan; mskhanfar@just.edu.jo \\ * Correspondence: ssnimry@just.edu.jo; Tel.: +962-797670604
}

check for

updates

Citation: Al-Nimry, S.S.; Khanfar, M.S. Validation of an RP-HPLC

Method for the Determination of

Asenapine Maleate in Dissolution

Media and Application to Study In Vitro Release from Co-Crystals. Sci.

Pharm. 2021, 89, 14.

https://doi.org/10.3390/

scipharm89010014

Academic Editor: Chih-Chien Lin

Received: 5 February 2021

Accepted: 2 March 2021

Published: 8 March 2021

Publisher's Note: MDPI stays neutral with regard to jurisdictional claims in published maps and institutional affiliations.

Copyright: (c) 2021 by the authors. Licensee MDPI, Basel, Switzerland. This article is an open access article distributed under the terms and conditions of the Creative Commons Attribution (CC BY) license (https:// creativecommons.org/licenses/by/ $4.0 /)$.

\begin{abstract}
Asenapine maleate is an antipsychotic drug that is indicated in the treatment of schizophrenia and bipolar disorders. It has low aqueous solubility and high permeability (Class II drug) and undergoes an extensive first pass effect. These problems result in low oral bioavailability $(<2 \%)$. To enhance its solubility/dissolution rate and hence bioavailability, co-crystals using different co-formers in different ratios were prepared and evaluated. To study the in vitro dissolution of the drug from these co-crystals into phosphate buffer ( $\mathrm{pH}$ 6.8), an RP-HPLC method was developed and validated according to the ICH Q2R1 guidelines. The method was linear in the range $0.1-14 \mu \mathrm{g} / \mathrm{mL}(\mathrm{R}>0.9998)$ and accurate and precise. An ANOVA test indicated that calibration curves run on different days did not differ significantly. It was sensitive (lower limit of quantitation (LLOQ) $=25.03 \mathrm{ng} / \mathrm{mL}$ ), specific (the co-formers did not interfere with the determination of the drug), and robust to small changes in the mobile phase ( $\mathrm{pH}$, composition, and flow rate). The in vitro release of asenapine maleate from the co-crystals and the physical mixture was much enhanced when compared to the in vitro dissolution of the unprocessed drug. In conclusion, the developed and validated RP-HPLC method met the acceptance criteria and was applied successfully in evaluating the in vitro release of the drug.
\end{abstract}

Keywords: asenapine maleate; RP-HPLC method; validation; co-crystals; application; in vitro release

\section{Introduction}

Asenapine maleate is an antipsychotic drug that is indicated in schizophrenia and bipolar disorders [1-3]. It has low aqueous solubility and high permeability (log P of $4.61 \pm 0.05$ and intrinsic solubility of $237 \pm 18 \mu \mathrm{g} / \mathrm{mL}$ ) [4]. It is a Class II drug according to the BCS [3]. It undergoes extensive first pass effect. It has low bioavailability after oral administration $(<2 \%)$, which increases after sublingual administration $(35 \%)$ [3,5-7].

Few methods for the determination of asenapine maleate in bulk, and pharmaceutical formulations including tablets and sublingual films, have been developed and validated [8-18]. Several methods indicating the stability of the drug in bulk and pharmaceutical formulations were also developed [18-23]. In preformulation studies, during the development of various dosage forms, several spectrophotometric [24-28] and HPLC [1,5,6,24,29-31] methods were used to determine drug loading and study in vitro release. Most of these studies just mention the kind of method without giving details. Few studies mention the details of the method without mentioning if it was validated or not. Only two studies mentioned the details of the method and the some of the results of the validation, but not the details of the validation $[5,6]$.

In the first method, an RP-HPLC method was developed using the Shimadzu LC2010CHT liquid chromatograph system with UV-detection and a PDA detector operated at $230 \mathrm{~nm}$. A Hyperclone BDS C18 $(250 \mathrm{~mm}, 4.6 \mathrm{~mm}, 5 \mu \mathrm{m})$ column maintained at $25^{\circ} \mathrm{C}$ was used. The mobile phase consisted of an 80:20\% $v / v$ mixture of $20 \mathrm{mM}$ phosphate buffer $(\mathrm{pH}$ 3.0) containing $0.1 \% v / v$ TEA and acetonitrile. The flow rate was $1 \mathrm{~mL} / \mathrm{min}$ and the injection 
volume $20 \mu \mathrm{L}$. The drug was retained at $7.6 \mathrm{~min}$. The method was validated according to the ICH guidelines in terms of system suitability, specificity, linearity, precision, and accuracy. The method met the suitability acceptance criteria (relative standard deviation (RSD) of the area $<2.0 \%$, tailing factor $<2.0$, and the theoretical number of plated was 42,000$)$. The method was specific, and the diluent and other materials did not interfere with the analysis of asenapine. The method was linear in the range studied; the correlation coefficient was 0.9998. The RSD was $<1.0 \%$ for both repeatability and intermediate precision, and the recovery was $97-101 \%$ [5].

Concerning the second method, an RP-HPLC method was developed using a Waters HPLC 515 system with a photodiode array detector at $268 \mathrm{~nm}$. A C18 spherisorb (250 mm, $4.6 \mathrm{~mm}, 5.0 \mu \mathrm{m}$ ODS) column connected with a guard ( $10 \mathrm{~mm}, 4.6 \mathrm{~mm}, 5.0 \mu \mathrm{m}$ ODS) column and maintained at $25^{\circ} \mathrm{C}$ was used. The mobile phase consisted of a 75:25 $v / v$ acetonitrile and $10 \mathrm{mM}$ phosphate buffer ( $\mathrm{pH}$ 3.3) adjusted with triethyl amine and orthophosphoric acid. The flow rate was $1.0 \mathrm{~mL} / \mathrm{min}$. The drug was retained at $4.076 \mathrm{~min}$. The method was validated according to the ICH guidelines with respect to system suitability, linearity, limit of quantification and detection, precision, accuracy, robustness, and specificity. It was linear in the range studied (10.0-100.0 $\mathrm{mg} \mathrm{mL}$ ), and the $\mathrm{R}^{2}$ was 0.9988 [6].

The dissolution test is an important tool during the preformulation study, in ensuring batch to batch consistency, and in proving that post approval changes did not affect the performance of the product (SUPAC). As such, there was no single study describing the validation process in detail. The objective of this research was to develop and validate a simple, accurate, precise, specific and robust HPLC-UV method for the determination of the drug in dissolution media, and to apply it successfully to study the in vitro release of the drug from different drug-co-former co-crystals.

A few steps were taken towards developing a green HPLC method [32-34]. The consumption of chemical reagents (triethylamine) and organic solvents (acetonitrile) in the preparation of the mobile phase was eliminated or reduced as compared with other methods (75\% acetonitrile) [6]. Triethylamine affects the interaction with the column and improves the peak shape $[35,36]$, but it shortens the life of the column. Organic solvents affect the health of the analysts and the environment.

\section{Materials and Methods}

\subsection{Materials}

Asenapine maleate (Lot \# 180427) was obtained from Baoji Guokang Bio-Technology Co., Ltd. (Baoji, Shaanxi, China). HPLC-grade Nicotinamide (Lot \# BCBZ8507), succinic acid bioreagent (Lot \# SLBN3066V) and urea bioreagent (Lot \# SLBT1918) were obtained from Sigma life science (Gillingham, UK). Chemically pure potassium dihydrogen phosphate (Lot \# 20161210) and absolute ethanol 99.9\% (Batch number GD9123750) were obtained from AZ chem for chemicals (Amman, Jordan). Ortho phosphoric acid 85\% (Lot \# 12090377) was obtained from RCI Labscan, Ltd. (Pathumwan, Bangkok, Thailand). HPLC gradient-grade methanol (Lot \# 1996473) and HPLC gradient-grade acetonitrile (Lot \# 1992658) were obtained from Fisher (Loughborough, UK). Ortho phosphoric acid 85\% (batch number 12090377) was purchased from RCI Labscan, Ltd. (Thailand).

\subsection{Methods}

\subsubsection{Preparation and Characterization of Co-Crystals}

The preparation of co-crystals was described elsewhere, but briefly, given weights of the drug and co-former in a 1:1 molar ratio were dissolved in ethanol using Langford sonicator (Belfast, UK) for $30 \mathrm{~min}$. Next, the solvent was rapidly removed using Heidolph Laborota 4010 digital rotatory evaporator (Schwabach, Germany) connected to a vacuum pump (Welch, NY, USA). The temperature of the water was set at $55^{\circ} \mathrm{C}$ and the rotation speed at $100 \mathrm{rpm}$. The resulting co-crystal products were collected and dried in an oven at $60{ }^{\circ} \mathrm{C}$. Other co-formers (succinic acid, nicotinamide, and urea) and other drug:co-former ratios (1:2 and 1:3) were tried. 
A physical mixture with the same molar ratio as the optimum batch of co-crystals was prepared by trituration in a pestle and mortar for $10 \mathrm{~min}$. The mixture was sieved using a sieve with an opening diameter of 425 micrometer and stored until used.

The co-crystals and the physical mixture were characterized by determining their drug content, PXRD (Powder X-ray Diffraction), DSC (Differential Scanning Calorimetry), FTIR (Fourier-Transform Infrared spectroscopy), and in vitro dissolution.

\subsubsection{HPLC System and Chromatographic Conditions}

A Shimadzu 10AV HPLC system (Shimadzu, Kyoto, Japan) at room temperature was used for the determination of asenapine maleate. It consisted of an LC-10 ADVP liquid chromatograph pump, an SIL-20 A prominence auto sampler, an SPD-10AVP UVvisible detector and an SCL-10AVP system controller. Initially a Eurospher C18 (Knauer, Berlin, Germany) column ( $250 \mathrm{~mm}, 4.0 \mathrm{~mm}$ ID $5 \mu \mathrm{m}$ ) was used. Multiple phosphate buffer:acetonitrile ratios were tested to achieve a reasonable run time and to avoid the co-elution of the drug and the co-formers. The $\mathrm{pH}$ of the phosphate buffer was kept blow the $\mathrm{pK}_{\mathrm{a}}$ of the drug by $\geq 2$ units to maintain the drug in the non-ionized form. Unfortunately, some of the co-formers (urea) coeluted with the drug. Finally, the column was changed to a Hypersil Gold ${ }^{\mathrm{TM}}(100 \mathrm{~mm} \times 4.6 \mathrm{~mm}$ ID, $5 \mu \mathrm{m}$ pore size) column (Lot number 16647) (Thermo Scientific, Dreieich, Germany). The mobile phase was acetonitrile: $10 \mathrm{mM}$ phosphate buffer $(30: 70, v / v)$ and its $\mathrm{pH}$ was adjusted to 3.5 using orthophosphoric acid. It was filtered using a regenerated cellulose membrane filter with a pore size of $0.45 \mu \mathrm{m}$. The flow rate was $1.0 \mathrm{~mL} / \mathrm{min}$, and the injection volume was $20 \mu \mathrm{L}$. The detection of the drug was at $\lambda_{\max }(220 \mathrm{~nm})$.

\subsubsection{Preparation of Solutions, Calibration Standards and Quality Control Samples}

A stock solution of asenapine maleate $(1000 \mu \mathrm{g} / \mathrm{mL})$ was prepared by dissolving $0.025 \mathrm{~g}$ of drug in methanol and completing the volume to $25 \mathrm{~mL}$. A working solution was prepared by withdrawing $5.0 \mathrm{~mL}$ from the stock and topping up the volume to $50 \mathrm{~mL}$ with methanol. Eight calibration standards $(0.1,0.5,1.0,2.0,4.0,8.0,10.0$, and $14.0 \mu \mathrm{g} / \mathrm{mL})$ were prepared from the working solution by serial dilution with methanol. Quality control (QC) samples were prepared by the same method. The concentrations of the QC Low, QC Mid, and QC High were $0.3,7.0$, and $12.0 \mu \mathrm{g} / \mathrm{mL}$, respectively.

\subsubsection{Validation}

A calibration curve consisting of 8 concentrations of asenapine maleate $(0.1,0.5,1.0$, 2.0, 4.0, 8.0, 10.0, and $14.0 \mu \mathrm{g} / \mathrm{mL}$ ) was constructed daily by plotting peak areas (y) of asenapine maleate against corresponding concentrations (x). Linear regression was used to obtain the intercept, slope, and coefficient of correlation (R). JMP statistical analysis software was used to conduct a one-way analysis of variance (ANOVA) test for evaluating the results. The significance level was $\alpha=0.05$ ( $95 \%$ of confidence interval).

The intra-day accuracy and precision at the Lower Limit of Quantitation (LLOQ) $(0.1 \mu \mathrm{g} / \mathrm{mL})$, and the intra- and inter-day accuracy and precision at Low QC, Mid QC and High QC $(0.3,7.0$ and $12.0 \mu \mathrm{g} / \mathrm{mL})$, were evaluated. Six LLOQ samples were run on day 1 and five QC samples at each concentration level were run on day 1 , day 2 , and day 3 . The accuracy was determined by comparing the assayed concentration with the nominal concentration. Accuracy is calculated as percentage of recovery [37] using the following equation:

$$
\text { Accuracy } \%=100-\left[\left(\frac{(\text { Theoritical value }- \text { Experimental value })}{\text { Theoritical value }}\right) \times 100 \%\right]
$$

Precision was determined by calculating the coefficients of variations (CV)/(RSD). 
The RSD is calculated using the following equation:

$$
R S D \%=\frac{\text { Standard deviation }}{\text { mean }} \times 100 \%
$$

JMP statistical analysis software was used to conduct a one-way ANOVA test for evaluating the results. The significance level was $\alpha=0.05$ ( $95 \%$ of confidence interval).

For the LOD (Limit of Detection) and LLOQ determination, the following equations were used, respectively.

$$
\begin{gathered}
L O D=\frac{3.3 * \sigma}{S} \\
L L O Q=\frac{10 * \sigma}{S}
\end{gathered}
$$

where $\sigma$ is the standard deviation (SD) of the response and s is the slope of the calibration curve.

The sensitivity of the method was reflected by the lowest concentration of the drug that could be quantitated accurately and precisely (LLOQ)). Experimentally, the first point in the calibration curve was set as the LLOQ $(0.1 \mu \mathrm{g} / \mathrm{mL})$. The accuracy and precision of the LLOQ were determined as in the "Intra- and inter-day accuracy and precision" section.

The specificity of the method was studied to ensure that the co-formers used in the preparation of co-crystals did not affect the determination of the drug. Samples were spiked with the co-formers at the highest concentration used in the test formulations. The chromatograms were checked to detect any peak present at the retention time $\left(t_{r}\right)$ of asenapine maleate.

Robustness was determined by making small changes in the mobile phase and studying the effect on resolution $\left(R_{S}\right)$, capacity factor $\left(k^{\prime}\right)$, theoretical plates number $(N)$ and asymmetry (As). These changes included changes in the composition of the mobile phase (acetonitrile:buffer ratio 28:72 and 32:68), the $\mathrm{pH}$ of the phosphate buffer (3.3 and 3.7), and the flow rate $(0.8$ and $1.2 \mathrm{~mL} / \mathrm{min})$. With each change, five $\mathrm{QC}$ samples at the three concentration levels were run. The mean at the nominal condition was compared to that the new condition.

\subsubsection{In Vitro Release Studies}

The in vitro release study was carried out using aUSP dissolution apparatus II, VanKel VK7000 Dissolution System with VK750D Heater Circulator (Varian, Inc., Palo Alto, CA, USA) set at $37 \pm 0.5^{\circ} \mathrm{C}$ and $75 \mathrm{rpm}$. Equivalent amounts of the co-crystals to $10 \mathrm{mg}$ of asenapine maleate were weighed and placed in the dissolution medium. The dissolution medium consisted of $900 \mathrm{~mL}$ phosphate buffer $\mathrm{pH}$ 6.8. Samples $(5 \mathrm{~mL})$ were withdrawn at $5,10,15,20,30,45,60,90$, and $120 \mathrm{~min}$. They were replaced directly with fresh dissolution medium kept at the same temperature. Samples were filtered using disposable $0.45 \mathrm{~mm}$ syringe filters. The concentration of the drug in these samples was determined using the calibration curve run on the same day according tothe developed and validated RP-HPLC method. The in vitro release studies were conducted in triplicate $(n=3)$ except for the drug-nicotinamide co-crystals, which were carried out in sextuplicate $(n=6)$. The in vitro release of the drug from the co-crystals was compared to that from the physical mixture and the unprocessed drug.

\section{Results}

\subsection{Method Validation}

The developed RP-HPLC method for the determination of asenapine maleate in the dissolution media was validated according to the ICH Guidelines Q2(R1) [38]. The validation parameters included linearity, accuracy and precision, sensitivity (lower limit of quantification (LLOQ)), specificity and robustness. 


\subsubsection{Linearity}

A chromatogram of the QC High is presented in Figure 1. The peak of asenapine maleate appeared at $5.158 \mathrm{~min}$. It was symmetrical and well resolved from the adjacent peaks.

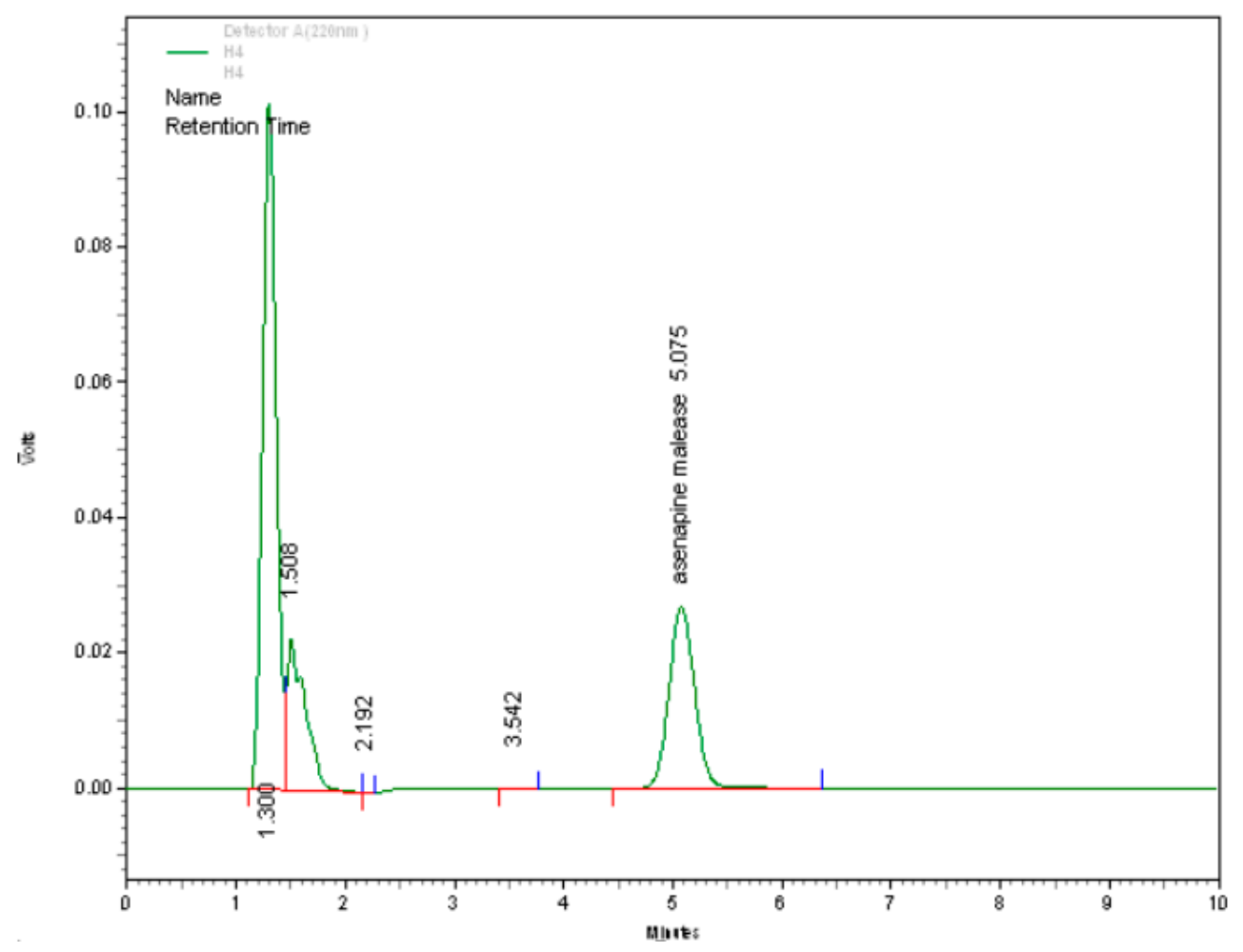

Figure 1. A chromatogram of the QC High sample of asenapine maleate $(12 \mu \mathrm{g} / \mathrm{mL})$. The green line is used to draw the chromatogram. The horizontal red line is used to integrate the peak area. The vertical red line indicates the start of the peak while the vertical blue indicates the end of the peak.

The linearity is the ability of the method to give results that are in direct proportionality with the amount of analyte in the sample [39]. It was evaluated by running six calibration curves on different days. Each calibration curve included eight calibration standards covering the range $0.1-14 \mu \mathrm{g} / \mathrm{mL}$. To construct the calibration curve, the peak area was plotted against the amount of the drug. Linear regression was used to obtain the intercept, slope, and $\mathrm{R}^{2}$, and the data are presented in Table 1 . The linear fit of the data is shown in Figure 2. The $\mathrm{R}$ value was $>0.9995$, which indicated that the data fitted the regression line acceptably [40]. The results of the ANOVA test for the calibration curves are shown in Table 2 . The $p$-value was $>0.05$, which indicated that the calibration curves run on different days did not differ significantly. 
Table 1. Linearity of the RP-HPLC method for the determination of asenapine maleate in dissolution media (parameters of the calibration curves) $(n=6)$.

\begin{tabular}{|c|c|c|c|c|c|c|c|c|c|c|c|}
\hline \multirow{3}{*}{$\begin{array}{l}\text { Calib. } \\
\text { Curve \# }\end{array}$} & \multicolumn{8}{|c|}{ Conc. $(\mu \mathrm{g} / \mathrm{mL})$} & \multirow{3}{*}{ Slope } & \multirow{3}{*}{ Intercept } & \multirow{3}{*}{$\mathbf{R}^{2}$} \\
\hline & 0.1 & 0.5 & 1 & 2 & 4 & 8 & 10 & 14 & & & \\
\hline & \multicolumn{8}{|c|}{ Area under the Peak } & & & \\
\hline 1 & 3768 & 17,276 & 36,890 & 76,744 & 154,435 & 310,322 & 377,191 & 536,969 & 38,312 & 444.35 & 0.9998 \\
\hline 2 & 3539 & 16,413 & 34,897 & 68,696 & 145,550 & 285,936 & 361,038 & 498,709 & 35,844 & 579.21 & 0.9999 \\
\hline 3 & 2846 & 15,543 & 34,995 & 63,027 & 121,823 & 267,408 & 329,266 & 449,850 & 32,534 & 450.44 & 0.9991 \\
\hline 4 & 3080 & 18,022 & 38,372 & 73,429 & 138,106 & 295,102 & 369,782 & 508,066 & 36,552 & 438.69 & 0.9996 \\
\hline 5 & 3215 & 16,194 & 35,921 & 75,730 & 151107 & 300,606 & 368,445 & 514,839 & 36,927 & 470.3 & 0.9998 \\
\hline 6 & 4551 & 16,004 & 35,087 & 71,747 & 147,177 & 287,246 & 365,097 & 508,659 & 36,384 & 656.84 & 0.9999 \\
\hline Mean & 3500 & 16,575 & 36,027 & 71,562 & 143,033 & 291,103 & 361,803 & 502,849 & & & \\
\hline SD & 610 & 911 & 1377 & 5076 & 11,772 & 14,688 & 16,821 & 28,965 & & & \\
\hline RSD & 17 & 5 & 4 & 7 & 8 & 5 & 5 & 6 & & & \\
\hline
\end{tabular}

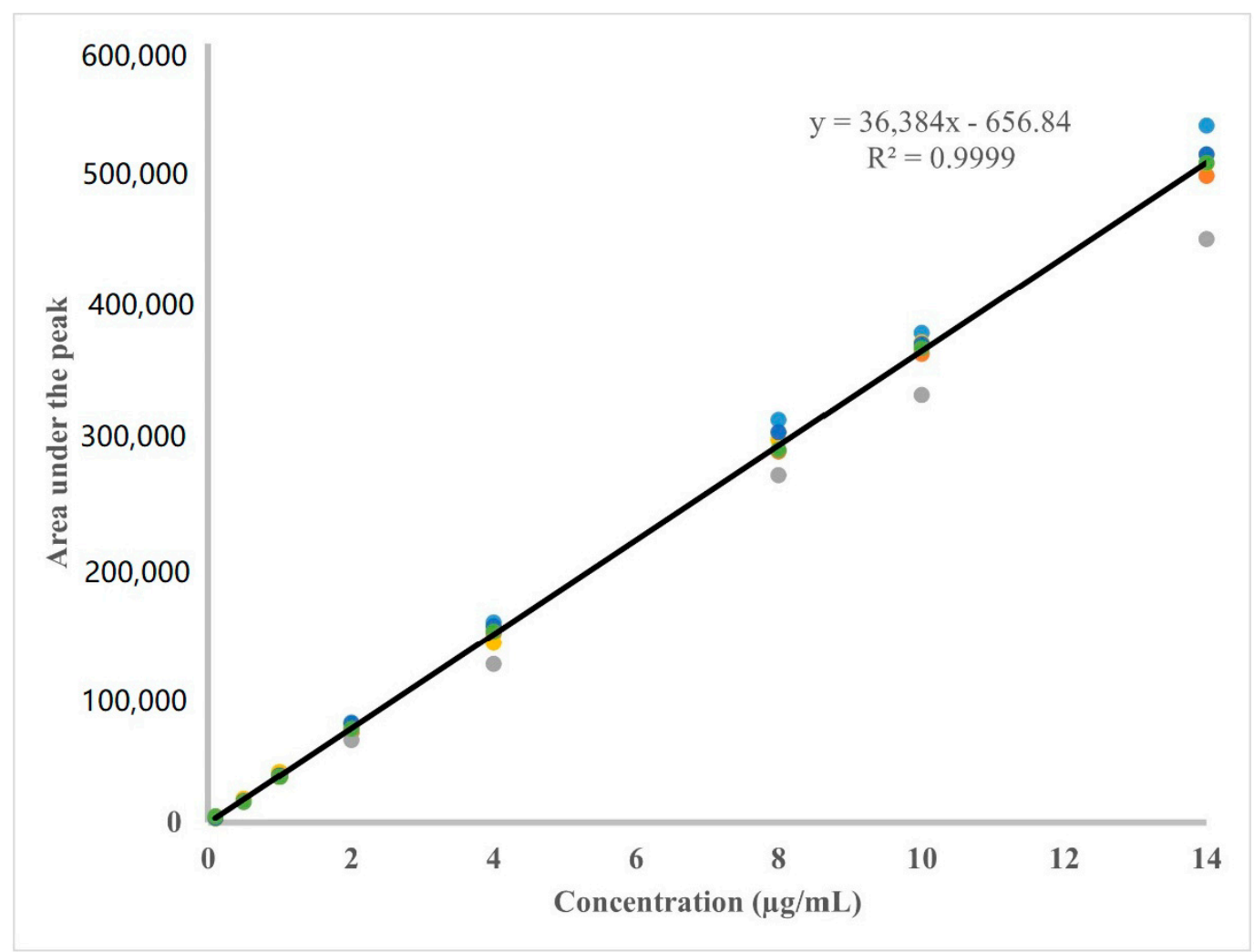

Figure 2. Linear fit of the calibration curves $(n=6)$. Each colour represents the eight points of a calibration curve $(6$ colours for 6 calibration curves). The solid black line represents the linear fit for the whole data.

Table 2. Results of the analysis of variance (ANOVA) test for the calibration curves data.

\begin{tabular}{cccccc}
\hline Source of Variation & DF & SS & MS & F Ratio & Prop > F \\
\hline Between groups & 7 & $1,447,908,839,267.33$ & $206,844,119,895.33$ & 1099.44 & 0 \\
Within group & 40 & $7,525,440,295.57$ & $188,136,007.39$ & & \\
Total & 47 & $1,455,434,279,562.89$ & & & \\
\hline
\end{tabular}

DF-degrees of freedom; SS-sum of squares; MS-mean square; $p<0.05$. 


\subsubsection{Accuracy and Precision}

Accuracy measures the agreement between the experimental value and the theoretical value of the analyte in the sample. At least nine determinations at three concentration levels within the range are used [38,40].

Precision measures the agreement between individual test results when the same method is applied repeatedly to several samplings of a homogeneous sample. Precision should be evaluated in terms of repeatability, intermediate precision, and reproducibility $[38,40]$. It can be reported as variance, SD, or as the (RSD) of a series of measurements.

Repeatability is the variation in assays on the same day obtained at different concentration levels using the same analyst and the same equipment. Intermediate precision is the variation in assays performed in the same laboratory on different days, or with different analysts or equipment [38,41]. Reproducibility is the variation in assays between laboratories [42].

The RSD between the two groups of data must be $\leq 2.0 \%[38,43]$. The intra- and interday accuracy and precision were determined using six QC Low, six Mid QC, and six High QC samples. These samples were run on day 1, day 2, and day 3. Additionally, six LLOQ samples were run on day 1 of the validation. The results are shown in Table 3. The data in Table 3 indicated that the accuracy and precision met the acceptance criteria $[38,44,45]$. The results of the ANOVA test for the QC samples are presented in Table 4. The $p$-value $>0.05$ indicated that the QC samples run on the same day or different days did not differ significantly.

Table 3. Intra- and inter-day accuracy and precision of the RP-HPLC method for the determination of asenapine maleate in dissolution media.

\begin{tabular}{cccccccc}
\hline QC & & \multicolumn{3}{c}{ Inter-Day Assay } & \multicolumn{3}{c}{ Inter-Day Assay } \\
\cline { 3 - 8 } $\begin{array}{c}\text { Samples } \\
(\mathbf{n}=\mathbf{6})\end{array}$ & $\begin{array}{c}\text { Conc. } \\
(\mu \mathrm{g} / \mathbf{m L})\end{array}$ & Mean & Accuracy & $\begin{array}{c}\text { Precision } \\
(\mathbf{C V} \%)\end{array}$ & Mean & Accuracy & $\begin{array}{c}\text { Precision } \\
\text { (CV \%) }\end{array}$ \\
\hline LLOQ & 0.10 & 0.10 & 101.00 & 3.71 & 0.10 & 104.62 & 6.62 \\
QC low & 0.30 & 0.29 & 97.85 & 5.50 & 0.30 & 99.67 & 3.43 \\
QC mid & 7.00 & 6.71 & 95.87 & 3.26 & 7.02 & 100.23 & 4.45 \\
QC high & 12.00 & 11.66 & 97.17 & 1.80 & 12.36 & 103.02 & 5.28 \\
\hline
\end{tabular}

Table 4. Results of the ANOVA test for the intra- and inter-day accuracy and precision data.

\begin{tabular}{|c|c|c|c|c|c|c|}
\hline Concentration Level & Source of Variation & DF & SS & MS & F Ratio & Prop $>$ F \\
\hline & between groups & 2 & 0.0004 & 0.0002 & 6.82 & 0.0078 \\
\hline \multirow[t]{3}{*}{ LLOQ } & within group & 15 & 0.0004 & 0 & & \\
\hline & Total & 17 & 0.0008 & & & \\
\hline & between groups & 2 & 0.0003 & 0.0002 & 1.837 & 0.2014 \\
\hline \multirow[t]{3}{*}{ QC Low } & within group & 12 & 0.0011 & 0.0001 & & \\
\hline & Total & 14 & 0.0015 & & & \\
\hline & between groups & 2 & 1.0562 & 0.5281 & 20.6702 & 0.0001 \\
\hline \multirow[t]{3}{*}{ QC Mid } & within group & 12 & 0.3066 & 0.0255 & & \\
\hline & Total & 14 & 1.3628 & & & \\
\hline & between groups & 2 & 4.8364 & 2..4182 & 25.5275 & 0 \\
\hline \multirow[t]{2}{*}{ QC High } & within group & 12 & 1.1368 & 0.0947 & & \\
\hline & Total & 14 & 5.9732 & & & \\
\hline
\end{tabular}

\subsubsection{Sensitivity}

The LOD is the smallest amount of analyte that can be detected but not exactly quantified. The LLOQ is the smallest amount of analyte that can be quantified accurately and precisely [32]. The calculated LOD was $8.26 \mathrm{ng} / \mathrm{mL}$ and the LLOQ was $25.03 \mathrm{ng} / \mathrm{mL}$. The experimental value of the LLOQ, the first point in the calibration curve, was $0.10 \mu \mathrm{g} / \mathrm{mL}$. 
The accuracy and precision of the LLOQ are presented in Table 3. The values met the acceptance criteria $[38,44,45]$, which indicates that the method was sensitive.

\subsubsection{Specificity}

Specificity is the ability of the method to determine the analyte accurately in the presence of other expected materials (impurities, degradation products, excipients, etc.) $[38,40]$. Chromatograms of the asenapine maleate at LLOQ $(1 \mu \mathrm{g} / \mathrm{mL})$ and of the co-formers at the highest concentrations used in the co-crystals (drug:co-former ratio 1:3) are shown in Figure 3 . The chromatogram of nicotinamide did not show any peak at the $t_{r}$ of the drug (5.375 $\mathrm{min})$, while those of succinic acid and urea showed small peaks close to the $t_{\mathrm{r}}$ of the drug. However, these peaks did not affect the determination of the drug; the calibration curve was linear, and the LLOQ and the QC samples at the three concentration levels met the acceptance criteria in terms of accuracy and precision.

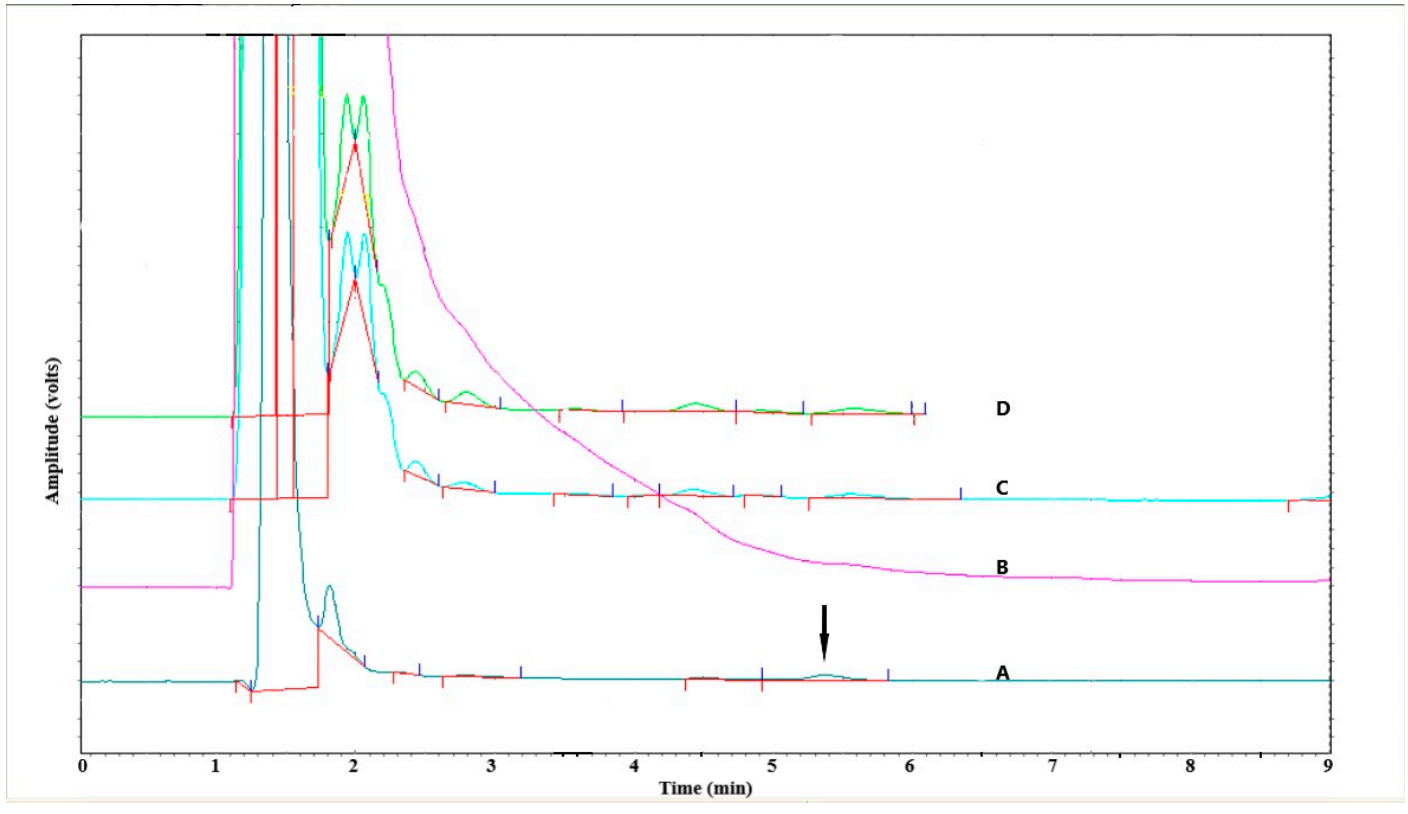

Figure 3. Chromatograms of (A) asenapine maleate $(1 \mu \mathrm{g} / \mathrm{mL})$ and the co-formers (B) nicotinamide, (C) urea, and (D) succinic acid used in the preparation of co-crystals, indicating the specificity of the method. The arrow indicates the peak of the drug.

\subsubsection{Robustness}

Robustness was determined by studying the effects of making small changes in the mobile phase on $R_{s}, k^{\prime}, N$ and As. These changes included changes in the composition of the mobile phase (Acetonitrile:buffer ratio 28:72 and 32:68), the $\mathrm{pH}$ of the phosphate buffer ( 3.3 and 3.7$)$, and the flow rate $(0.8$ and $1.2 \mathrm{~mL} / \mathrm{min})$. With each change, five QC samples at each concentration level were run. The mean at the nominal condition was compared to the mean after making the small changes. $R_{\mathrm{S}}$ is a measure of how well the peak of analyte and the closest interfering peak are separated. A value of $R_{\mathrm{S}}>2$ indicates well resolved peaks $[46,47]$. As shown in Table 5, the peaks were well resolved in the nominal condition and when small changes were made in the method. $\mathrm{k}^{\prime}$ is a measure of the retention of an analyte on the chromatographic column. A higher $\mathrm{k}^{\prime}$ value indicates strong binding of the sample to the stationary phase of the column. $K^{\prime}$ values between 1 and 10 are considered good [46,47]. As is clear from the table, the $\mathrm{k}^{\prime}$ values were above 1 in the nominal condition, and small changes were made in the method that indicated the good retention of the analyte. N measures the peak dispersion on the HPLC column and indicates the column performance. In general, $\mathrm{N}$ values should be $>2000$. With higher $\mathrm{N}$ values, narrower peaks and better resolutions are obtained [46,47]. $\mathrm{N}$ was greater than 2000 
in the nominal condition and when the $\mathrm{pH}$ of the mobile phase was changed to 3.30, which indicated the good performance of the column. However, $\mathrm{N}$ was less than, but close to, 2000 when the flow rate was changed, and it was around 1200 when the $\mathrm{pH}$ was changed to 3.70. In spite of that, the other parameters at these conditions indicated good retention on the column, good resolution, and the symmetry of the peaks.

Table 5. Results of the robustness showing the effect of making small changes in the composition, $\mathrm{pH}$ and flow rate.

\begin{tabular}{llllll}
\hline Parameters Studied & & $\mathbf{R}_{\mathbf{s}}$ & $\mathbf{k}$ & $\mathbf{N}$ & $\mathbf{A}_{\mathbf{s}}$ \\
\hline \multirow{2}{*}{ Flow rate (mL/min) } & $\mathbf{0 . 8 0}$ & 7.88 & 4.00 & 1644.68 & 1.85 \\
& $\mathbf{1 . 2 0}$ & 4.53 & 2.23 & 1819.72 & 1.76 \\
pH of the buffer & $\mathbf{3 . 3 0}$ & 10.89 & 2.86 & 2436.00 & 0.98 \\
& $\mathbf{3 . 7 0}$ & 8.40 & 2.92 & 1187.55 & 1.41 \\
Buffer:acetonitrile & $\mathbf{6 8 : 3 2}$ & 8.27 & 2.04 & 2171.01 & 1.24 \\
& $\mathbf{7 2 : 2 8}$ & 12.17 & 3.80 & 2380.00 & 1.06 \\
\hline Nominal condition & & 10.89 & 2.86 & 2178.07 & 1.20 \\
\hline Target & $\mathbf{> 2}$ & $1<\mathrm{k}^{\prime}<10$ & $>2000$ & $\leq 2$ \\
\hline
\end{tabular}

Asymmetry (tailing or fronting) in the peak shape generally affects its resolution and quantitation. This decreases the accuracy of the method because it becomes difficult to determine the peak end and area. It is recommended to keep asymmetry values $\leq 2[46,47]$. This was achieved in the nominal condition and when small changes were made in the method. Accordingly, the results indicated that the method was rigid and robust to small changes in the chromatographic conditions.

\subsection{In Vitro Release Studies}

The in vitro release of the drug from the prepared co-crystals using different coformers in different ratios did not differ significantly (data not shown), and it was much higher as compared to that of the in vitro dissolution of the unprocessed drug. This could be explained by the fact that the co-crystals had lower melting points than the unprocessed drug.

The in vitro release rates of asenapine maleate from drug-urea co-crystals, drugsuccinic acid co-crystals, drug-nicotinamide co-crystals and a drug-nicotinamide physical mixture with the same molar ratio (1:3), and the in vitro release rate of the unprocessed drug, are presented in Figure 4. As is clear from Figure 4, when comparing the release from the different co-crystals, the cumulative amount released from the drug-succinic acid co-crystals was significantly less than that released from drug-nicotinamide and drug-urea co-crystals. Even though the cumulative amount of drug released from nicotinamide co-crystals and urea co-crystals was almost the same, the rate was different. A faster drug release was achieved from drug-nicotinamide co-crystals. Almost $48.45 \%$ of the drug was released from drug-nicotinamide co-crystals after $5 \mathrm{~min}$ as compared to 31.97 from the drug-urea co-crystals (there was no overlapping in the error bars ( $\pm \mathrm{SD})$ ). Similarly, even though the final amount of drug released from drug-nicotinamide and drug-urea cocrystals was similar to that from the physical mixture, the release rate was different. Faster drug release was achieved from the co-crystals. Almost $48.45-76.27 \%$ and $31.97-58.20 \%$ of the drug was released from drug-nicotinamide and drug-urea co-crystals, respectively, after 5-10 min, as compared to $0.82-12.78$ from the physical mix. This could be explained by the fact that the physical mixture had a higher melting point $\left(110.4^{\circ} \mathrm{C}\right)$ than the co-crystals $\left(98.3^{\circ} \mathrm{C}\right)$, and lower solubility. Accordingly, asenapine maleate-nicotinamide co-crystals having a ratio of 1:3 were considered as the optimum batch. 


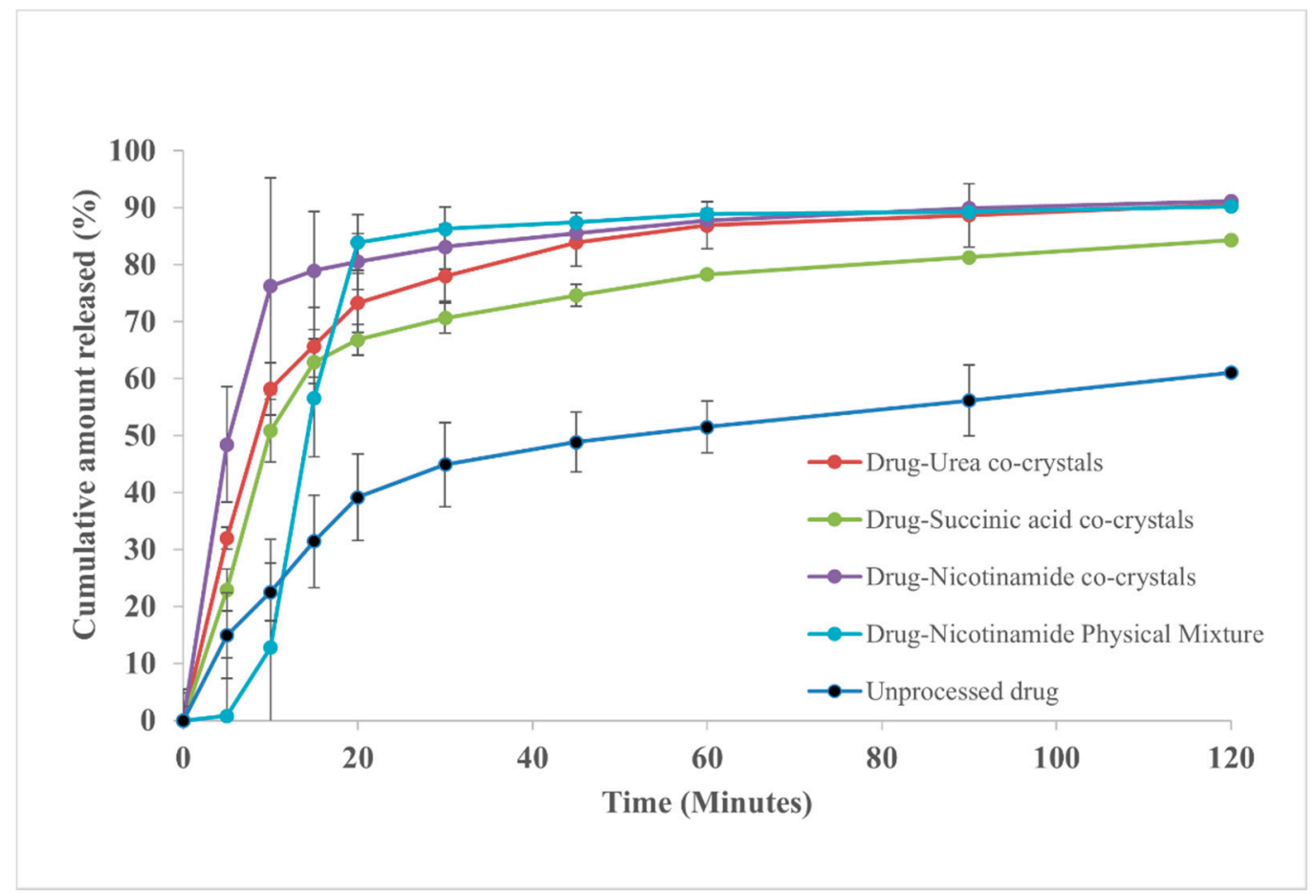

Figure 4. The in vitro dissolution of asenapine maleate from drug-urea co-crystals, drug-succinic acid co-crystals, drugnicotinamide co-crystals and drug-nicotinamide physical mixture in ratio 1:3 in $900 \mathrm{~mL}$ phosphate buffer $\mathrm{pH} 6.8$ at $37 \pm 0.5^{\circ} \mathrm{C}$ and $75 \mathrm{rpm}$.

\section{Conclusions}

An RP-HPLC method with a UV-Vis detector for the determination of asenapine maleate in phosphate buffer $\mathrm{pH} 6.8$ was developed and validated according to the $\mathrm{ICH}$ Guidelines Q2 (R1). It was linear in the range of $0.1-14 \mu \mathrm{g} / \mathrm{mL}$, and accurate and precise as indicated by the ANOVA test. It was specific to the drug, and the co-formers used in preparing the co-crystals did not interfere with the determination of its concentration. The method was robust to small changes in the chromatographic conditions. It was successfully applied in studying the in vitro release of asenapine maleate from the prepared co-crystals.

As mentioned in the introduction, to the knowledge of the authors, there is no single article before now describing the development and validation of an HPLC-UV method for the determination of asenapine maleate in dissolution media. The method is novel, and it has many advantages as compared to other methods. It is simple; single UV detection and isocratic elution of the mobile phase were used. The $t_{\mathrm{r}}$ of the drug was $5.158 \mathrm{~min}$ and the run time was shortened to 6.0 or $6.5 \mathrm{~min}$. Thus analysis of a large number of samples could be achieved in a short time, avoiding the degradation of the drug in the auto sampler. The injection volume was small $(20 \mu \mathrm{L})$, and thus avoided the broadening of the peak, and it maintained good resolution without the use of additional chemical reagents like TEA. The consumption of chemical reagents (TEA) and organic solvents (acetonitrile) in the preparation of the mobile phase was either eliminated or reduced. The run time was shortened, and the flow rate was optimized $(1.0 \mathrm{~mL} / \mathrm{min})$. The amount of acetonitrile produced per sample, based on the run time, flow rate and composition of the mobile phase, was less than $3 \mathrm{~mL}$ per sample, which is not difficult to recycle. All of this minimized the amount of waste and helped in protecting the operators and the environment.

The in vitro release of the drug from the optimized co-crystals (drug-nicotinamide in 1:3 ratio) was much enhanced/faster as compared to that from the physical mixture and from the unprocessed drug. 
Author Contributions: Conceptualization, S.S.A.-N. and M.S.K.; methodology, S.S.A.-N.; writingoriginal draft preparation, S.S.A.-N.; writing—review and editing, S.S.A.-N.; funding acquisition, S.S.A.-N. All authors have read and agreed to the published version of the manuscript.

Funding: This research was funded by [Deanship of scientific research at Jordan University of Science and Technology] grant number [129/2019].

Institutional Review Board Statement: Not applicable.

Informed Consent Statement: Not applicable.

Data Availability Statement: It will be supplied upon request.

Conflicts of Interest: The authors declare no conflict of interest.

\section{References}

1. Avachat, A.M.; Kapure, S.S. Asenapine maleate in situ forming biodegradable implant: An approach to enhance bioavailability. Int. J. Pharm. 2014, 477, 64-72. [CrossRef] [PubMed]

2. Kulkarni, J.A.; Avachat, A.M.; Avachat, C.M.; Pradhan, R.; Suryawanshi, T.S.; Khan, E.M.; Martis, E.A.; Coutinho, E.C.; Padhye, S. Preferential formulation of second generation antipsychotic asenapine as inclusion complex with sulphobutylether- $\beta C D$ (captisol): In vitro and in vivo evaluation. Curr. Drug Deliv. 2018, 15, 520-531. [CrossRef]

3. Gambhire, V.M.; Ranpise, N.S. Enhanced oral delivery of asenapine maleate from solid lipid nanoparticles: Pharmacokinetic and brain distribution evaluations. Asian J. Pharm. Sci. 2018, 12, 152-161.

4. Managuli, R.S.; Gourishetti, K.; Shenoy, R.R.; Koteshwara, K.B.; Reddy, M.S.; Mutalik, S. Preclinical pharmacokinetics and biodistribution studies of asenapine maleate using novel and sensitive RP-HPLC method. Bioanalysis 2017, 9, 1037-1047. [CrossRef] [PubMed]

5. Shreya, A.B.; Managuli, R.S.; Menon, J.; Kondapalli, L.; Hegde, A.R.; Avadhani, K.; Menon, J.; Kondapalli, L.; Hegde, A.R.; Avadhani, K.; et al. Nano-transfersomal formulations for transdermal delivery of asenapine maleate: In vitro and in vivo performance evaluations. J. Liposome Res. 2015, 26, 221-232. [CrossRef] [PubMed]

6. Singh, S.K.; Dadhania, P.; Vuddanda, P.R.; Jain, A.; Velagac, S.; Singh, S. Intranasal delivery of asenapine loaded nanostructured lipid carriers: Formulation, characterization, pharmacokinetic and behavioural assessment. RSC Adv. 2016, 6, 2032-2045. [CrossRef]

7. Kulkarni, J.A.; Avachat, A.M. Pharmacodynamic and pharmacokinetic investigation of cyclodextrin mediated asenapine maleate in situ nasal gel for improved bioavailability. Drug Dev. Ind. Pharm. 2017, 43, 234-245. [CrossRef] [PubMed]

8. Arelly, K.; Thimmaraju, M.K.; Nerella, R.; Allabotharam, S. Method development and validation of asenapine in bulk by RP-HPLC method. J. Chem. Pharm. Res. 2012, 4, 2580-2584.

9. Halima, O.A.; Aneesh, T.P.; Reshma, G.; Thomas, N.R. Development and validation of UV spectrophotometric method for the estimation of asenapine maleate in bulk and pharmaceutical formulation. Der Pharma Chem. 2012, 4, 644-649.

10. Parthasarathi, T.R.; Srinivas, T.S.; Sri, M.V.; Ram, S.S.; Mahaboob Basha, M.; Rajesh, P. Quantitative determination of asenapine maleate using reverse phase-high performance liquid chromatography. Int. J. Pharm. Bio. Sci. 2012, 3, 360-366.

11. Gandhimathi, R.; Vijayaraj, S.; Jyothirmaie, M.P. Method development and validation of UV spectroscopic method for estimation of asenapine maleate in bulk and tablet formulation. IJMCA 2012, 12, 85-90.

12. Mrudulesh, Y.; Sankar, P.R.; Devadasu, C.H.; Babu, P.S. Development of a validated UV spectrophotometric method for the quantitative estimation of asenapine maleate in bulk drug. J. Chem. Pharm. Sci. (JCPS) 2013, 6, 227-230.

13. Yanamadala, G.; Ramamohan, G.V.; Praveen, S.P.; Rusyendra, G.V.; Lavanya, N. Development and validation of RP-HPLC method for the estimation of asenapine maleate in bulk and pharmaceutical dosage forms. AJPAMC 2013, 1, $132-139$.

14. Govindarajan, N.R.; Koulagari, S.; Methuku, A.; Podhuturi, S. Method development and validation of RP-HPLC method for determination of new antipsychotic agent asenapine maleate in bulk and pharmaceutical formulation. Eurasian J. Anal. Chem. 2014, 9, 58-65.

15. Patel, P.S.; Patel, C.N.; Patel, M.M. Method development and validation of RP-HPLC for estimation of asenapine maleate in bulk drug and tablet dosage form. Int. J. Pharm. Res. Sci. (IJPRS) 2016, 5, 15-19.

16. Borkar, A.A.; Gaikwad, N.J. UV Spectrophotometric and RP-HPLC estimation of drug asenapine in tablet dosage form. IJPSR 2016, 7, 3080-3084. [CrossRef]

17. Patel, K.; Joshi, D.; Kumbhani, J.; Prajapati, V. HPLC Method Development for Estimation of Dissolution of Antipsychotic Drug as Sublingual Film Dosage Form. Chem. Sci. Trans. 2018, 7, 420-423. [CrossRef]

18. Ramadan, N.K.; Mohamed, T.A.; Fouad, R.M.; Moustafa, A.A. Potentiometric Determination of Asenapine Maleate Using PVC Membrane and Carbon Paste Ion-selective Electrodes. OMCIJ 2018, 8, 555726-555735. [CrossRef]

19. Aneesh, T.P.; Rajasekaran, A. Stress Degradation studies and development and validation of RPHPLC method for the estimation of Asenapine maleate. Int. J. Pharm. Pharm. Sci. 2012, 4, 448-451.

20. Chhalotiya, U.K.; Bhatt, K.K.; Shah, D.A.; Patel, J.R. Stability-indicating liquid chromatographic method for the quantification of the new antipsychotic agent asenapine in bulk and in pharmaceutical formulation. Sci. Pharm. 2012, 80, 407-417. [CrossRef] 
21. Managuli, R.S.; Kumar, L.; Chonkar, A.D.; Shirodkar, R.K.; Lewis, S.; Koteshwara, K.B.; Reddy, M.S.; Mutalik, S. Development and validation of a stability-indicating RP-HPLC method by a statistical optimization process for the quantification of asenapine maleate in lipidic nanoformulations. J. Chromatogr. Sci. 2016, 54, 1290-1300. [CrossRef]

22. Shyamala; Swarupa, A.; Anitha, P. Validated stability-indicating RP-HPLC method for determination of asenapine. Indo Am. J. Pharm. Sci. (IAJPS) 2018, 5, 4107-4113. [CrossRef]

23. Kalpana, G.L.; Devalarao, G.; Raju, M.B.; Praveenkumar, T. Validated stability indicating high performance liquid chromatographic method for the quantification of asenapine maleate. Int. J. Pharm. Pharm. Sci. 2015, 7, 61-65.

24. Chowdary, A.K.; Suravarapu, N.L.R.; Meddala, S. Formulation and characterization of asenapine maleate nanoparticles. Int. J. Pharm. Sci. Rev. Res. 2016, 40, 1-5.

25. Naik, B.; Gandhi, J.; Shah, P.; Naik, H.; Sarolia, J. Asenapine maleate loaded solid lipid nanoparticles for oral delivery. Int. Res. J. Pharm. 2017, 8, 45-53. [CrossRef]

26. Supriya, A.; Sundaraseelan, J.; Murthy, B.R.S.; Priya, M.B. Formulation and evaluation of capsules of asenapine maleate loaded chitosan nanoparticles. ASPS 2018, 2, 29-37.

27. Patel, M.H.; Mundada, V.P.; Sawant, K.K. Novel drug delivery approach via self-microemulsifying drug delivery system for enhancing oral bioavailability of asenapine maleate: Optimization, characterization, cell uptake, and in vivo pharmacokinetic studies. AAPS PharmSciTech 2019, 20, 44. [CrossRef] [PubMed]

28. Sahoo, S.; Malviya, K.; Kumar, S.; Golwala, V.D.K.; Mohapatra, P.K. Formulation and evaluation of sublingual tablets of asenapine maleate by 32 full factorial design. Aegaeum J. (AJ) 2020, 8, 1236-1250.

29. Blatter, F.; Reichenbacher, K. Novel Crystalline Salts of Asenapine with Organic di-Acids and Tri-Acids. U.S. Patent WO 2012/156383 Al, 21 November 2012.

30. Managuli, R.S.; Wang, J.T.; Faruqu, F.N.; Kushwah, V.; Raut, S.Y.; Shreya, A.B.; Al-Jamal, K.T.; Jain, S.; Mutalik, S. Asenapine maleate-loaded nanostructured lipid carriers: Optimization and in vitro, ex vivo and in vivo evaluations. Nanomedicine 2018, 14, 889-910. [CrossRef]

31. Managuli, R.S.; Wang, J.T.-Z.; Faruqu, F.M.; Pandey, A.; Jain, S.; Al-Jamal, K.T.; Mutalik, S. Surface engineered nanoliposomal platform for selective lymphatic uptake of asenapine maleate: In vitro and in vivo studies. Mater. Sci. Eng. C 2019, 109. [CrossRef]

32. Tzanavaras, P.D. A green HPLC method for the determination of n-acetylcysteine using post-column derivatization with methyl-propiolate. Instrum. Sci. Technol. 2012, 40, 150-160. [CrossRef]

33. Yabré, M.; Ferey, L.; Somé, T.I.; Sivadier, G.; Gaudin, K. Development of a green HPLC method for the analysis of artesunateand amodiaquine impurities using quality by design. J. Pharm. Biomed. Anal. 2020, 190, 113507-113516. [CrossRef] [PubMed]

34. Duan, X.; Liu, X.; Dong, Y.; Yang, J.; Zhang, J.; He, S.; Yang, F.; Wang, Z.; Dong, Y. A green HPLC method for determination of nine sulfonamides in milk and beef, and its greenness assessment with analytical eco-scale and greenness profile. J. AOAC Int. 2020, 103, 1-9. [CrossRef] [PubMed]

35. Chuang, C.-Z.; Ragan, F.A., Jr.; Prasad, C. Use of Triethylamine as an Ion-Pairing Reagent. J. Liq. Chromatogr. 1994, 17, $2383-2394$. [CrossRef]

36. Park, J.H.; Ryu, Y.K.; Lim, H.J.; Lee, H.S.; Park, J.K.; Lee, Y.K.; Jang, M.D.; Suh, J.K.; Carr, P.W. Effect of triethylamine in the mobile phase on the retention properties of conventional polymeric and horizontally polymerized octadecylsilica in RPLC. Chromatographia 1999, 49, 635-642. [CrossRef]

37. United States Pharmacopeia and National Formulary (USP30-NF25); 1225, Validation of Compendial Procedures; United States Pharmacopeial Convention: Rockville, MD, USA, 2007.

38. Validation of Analytical Procedures. Text and Methodology. In Proceedings of the International Conference on Harmonisation of Technical Requirements for Registration of Pharmaceuticals for Human Use, Q2(R1), Geneva, Switzerland, 1-13 November 2005.

39. Karim, S.; Hay, K.Y.; Baie, S.H.; Bukhari, N.I.; Murtaza, G. Study of comparative bioavailability of omeprazole pellets. Acta Pol. Pharm. 2014, 71, 463-468. [PubMed]

40. Suresh, R.; Anarthanan, S.; Manavalan, R.; Valliappan, K. Aspects of validation in HPLC method development for pharmaceutical analysis-comparison of validation requirements by FDA, USA and ICH. Int. J. Pharm. Sci. Res. 2010, 12, $123-133$.

41. Rao, R.; Talluri, M.V.; Raju, A.N.; Shinde, D.D.; Ramanjaneyulu, G.S. Development of a validated RP-LC/ESI-MS-MS method for separation, identification and determination of related substances of tamsulosin in bulk drugs and formulations. J. Pharm. Biomed. Anal. 2008, 46, 94-103.

42. Reddy, L.S.; Reddy, S.L.N.P.; Reddy, G.S. Development and validation of a stability indicating liquid chromatographic method for simultaneous estimation of dutasteride and tamsulosin in combined dosage form. Orient J. Chem. 2013, 29, 1665-1673. [CrossRef]

43. Tiwari, G.; Tiwari, R. Bioanalytical method validation: An updated review. Pharm. Methods 2010, 1, 25-38. [CrossRef]

44. Lindholm, J. Development and Validation of HPLC Methods for Analytical and Preparative Purposes. Master Thesis, Acta Universitatis Upsaliensis, Uppsala, Sweden, 2004.

45. US Food and Drug Administration. Guidance for Industry-Bioanalytical Method Validation; US Food and Drug Administration: Rockville, MD, USA, 2001.

46. US Food and Drug Administration. Reviewer Guidance: Validation of Chromatographic Method; US Food and Drug Administration: Rockville, MD, USA, 1994.

47. CHROMacademy. The Theory of HPLC Chromatographic Parameters. Available online: http://www.Chromacademy.com (accessed on 24 February 2019). 